University of Nebraska - Lincoln

DigitalCommons@University of Nebraska - Lincoln

USDA National Wildlife Research Center - Staff Publications
U.S. Department of Agriculture: Animal and Plant Health Inspection Service

June 2002

\title{
A comparison of four rodent control methods in Philippine experimental rice fields
}

\author{
Md. Sayed Ahmed \\ BASF Corporation, Princeton, NJ \\ Lynwood A. Fiedler \\ U.S. Department of Agriculture, Animal and Plant Health Inspection Service, National Wildlife Research \\ Center
}

Follow this and additional works at: https://digitalcommons.unl.edu/icwdm_usdanwrc

Part of the Environmental Sciences Commons

Ahmed, Md. Sayed and Fiedler, Lynwood A., "A comparison of four rodent control methods in Philippine experimental rice fields" (2002). USDA National Wildlife Research Center - Staff Publications. 454. https://digitalcommons.unl.edu/icwdm_usdanwrc/454

This Article is brought to you for free and open access by the U.S. Department of Agriculture: Animal and Plant Health Inspection Service at DigitalCommons@University of Nebraska - Lincoln. It has been accepted for inclusion in USDA National Wildlife Research Center - Staff Publications by an authorized administrator of DigitalCommons@University of Nebraska - Lincoln. 


\title{
A comparison of four rodent control methods in Philippine experimental rice fields
}

\author{
Md. Sayed Ahmed ${ }^{\mathrm{a}, 1}$, Lynwood A. Fiedler ${ }^{\mathrm{b}, *}$ \\ ${ }^{a}$ BASF Corporation, Quakerbridge and Clarkstille Roal, P.O. Box 400, Princeton, NJ 08543-(040), USA \\ ${ }^{\circ}$ U.S. Department of Agriculture. Animal and Plant Health Inspection Service, National Wildife Research Center. 4lol LaPorte Ate'., \\ Fort Collins. CO $80521-2154$. USA
}

\begin{abstract}
Four rodent control techniques-sustained baiting (SB) with coumachlor, pulsed baiting (PB) with brodifacoum, a lethal clectrified barrier (LEB), and a nonlethal clectrified barrier (NLEB) - were cvaluated on the experimental farm of the International Rice Research Institute (IRRI) in the Philippines. A fifth treatment (no experimental rodent control) was established for reference. Mean tiller damage and rodent activity, respectively, near harvest were $1.0 \%$ and $1.5 \%$ in the LEB plots, $1.6 \%$ and $18.0 \%$ in the SB plots, $2.1 \%$ and $16.0 \%$ in the PB plots, and $4.1 \%$ and $32.5 \%$ in the NLEB plots. Highest mean tiller damage $(9.3 \%)$ and rodent activity $(56.0 \%)$ occurred in plots with no experimental rodent control. Both baiting methods (SB and PB) were less expensive than barrier methods (LEB and NLEB). During an 80-day crop protection period prevalent on the IRRI experimental farm, the total cost per hectare (US\$) for protecting experimental plots from rodent damage was \$26 for SB, \$27 for PB, \$268 for NLEB, and \$1285 for LEB.

Baiting methods were more cost-effective and are recommended for general rodent control on research farms that can tolerate $\leqslant 2 \%$ rodent damage without losing experimental data. For small rescarch plots demanding a greater degree of protection, an effective barrier system such as the LEB or a combination of the NLEB and LEB should be used. Published by Elsevier Science Ltd.
\end{abstract}

Ke'words: Rodent control; Rodenticide baiting; Sustained baiting; Pulsed baiting; Barriers; Electric fences; Coumachlor; Brodifacoum; Ricefield rats

\section{Introduction}

Among vertebrates, rodents are the most damaging to Philippine rice, sometimes causing total crop loss. Rodents are also a serious problem in experimental plots causing unpredictable yield losses and unreliable research results. The International Rice Research Institute (IRRI) at Los Baños, Philippines, has about 252 ha of experimental fields in which Rattus rattus mindanensis $(=R$. tanezumi $)$ causes an estimated annual loss of rice-based crop research data valued at $\$ 370000$ (Ahmed et al., 1987). Attempts to limit these losses have required continuous, intense efforts that are difficult and costly.

Chemical control of rodents is usually the most cost-effective method, but success depends on the effectiveness of the chemical, attractiveness of the bait material and bait holder, as well as proper bait placement and timing. Sustained baiting (SB) with multiple-dose anticoagulant

\footnotetext{
* Corresponding author. Tel: +1-970-266-6077; fax: +1-970266-6089.

E-mail address: lynwood.a.fiedler(a aphis.usda.gov (L.A. Fiedler).

${ }^{\prime}$ Formerly, Bangladesh Rice Research Institute, Gazipur. Bangladesh.
}

rodenticides was developed in Philippine rice fields by West et al. (1975a). By offering an alternate food (anticoagulant bait) continuously from early transplanting to the maturing stages of rice, this method aims to reduce rodent populations within and around individual rice paddies so that maturing rice (preferred by rodents over bait material) receives only minimal damage at harvest (Fall, 1982).

Resistance of some rodent populations in temperate countries to multiple-dose anticoagulant rodenticides encouraged the development of second-generation anticoagulants that are lethal following a single ingestion of bait. This characteristic provided for a different rodent control strategy called pulsed baiting $(\mathrm{PB})$ in which animals that take a lethal dose during the first anticoagulant baiting are eliminated prior to a second baiting, and so on (Dubock, 1982). Theoretically, $\mathrm{PB}$ requires less bait and results in lower labour costs compared to SB.

Barriers can exclude rodents from crops, but are ineffective where rodents burrow under, climb over, or enter through accidental barrier openings. Lethal electrified barriers (LEB) protected valuable experimental rice plots at the IRRI farm from rodent damage (Ramos, 1970) but they 
were costly, laborious to install, and difficult to maintain. Because of these disadvantages and potential hazards to nontarget species, a nonlethal electrified barrier (NLEB) was developed for the Philippines (Shumake et al., 1979). The NLEB was more economical than the LEB and did not require night crews to remove electrocuted rodents or require daily battery recharges.

Prior to our study, the LEB was the only method of the four methods described to have been consistently used at the IRRI research farm. This study made an objective comparison of these methods concerning their efficacy and relative cost to protect rice grown on research plots.

\section{Methods}

Five treatments were evaluated: SB, PB, LEB, NLEB, and no experimental rodent control (NERC). Ten experimental plots (about 0.25 ha each) containing high-yielding rice varieties at 4 weeks after transplant (WAT) were used as test plots in the 1980 wet and 1981 dry planting seasons. During each season, two replications of five treatments were assigned to plots spaced $>90 \mathrm{~m}$ apart to minimize interplot treatment effects. Four plots were randomly assigned barrier treatments for the 1980 season. SB, PB, and NERC treatments were randomly assigned to the remaining six plots. During the 1981 dry season, the barricr-treated plots were reversed (i.e., LEB plots became NLEB plots and vice versa) and the SB, PB, and NERC plots were again randomly assigned to the remaining six plots. Cost of materials adjusted for life expectancy, and labour required to install, operate, and maintain cach method were recorded; and total costs per hectare per 80 -day crop protection period were calculated.

\subsection{Baiting methods}

Bait holders used in baited plots were made from two pieces of coconut husk (with coir), pierced and supported by a bamboo stick. The larger top piece protected bait in a smaller, lower husk from rain while the pointed bamboo stick anchored the assembled holder in the ground. All bait holders were removed 1 week before harvest. Intake by rodents was assumed to be the amount of bait added less the amount of bait remaining between observations. Any moldy or wet bait was removed, dried, weighed, and replaced with fresh bait.

To evaluate SB, a multiple-dose anticoagulant rodenticide bait was prepared by mixing $1 \%$ coumachlor [3-( $x$-acetonyl- $p$-chlorobenzyl $)-4$-hydroxycoumarin] with broken rice $(1: 35)$ to yield a $0.028 \%$ finished bait material. Five coconut husk bait holders, each with $50 \mathrm{~g}$ of bait, were positioned-four on the dike (one at each comer) and one in the middle of the plot. Bait was checked twice per week throughout the growing season and if disappearance at any holder exceeded $50 \%$ between inspections, an additional bait holder was added. Bait in each holder was replenished when more than $50 \%$ was consumed. The number of bait holders was reduced at points with little or no consumption for two consecutive inspections, but at least one holder was always maintained at each of the five initial baiting points.

To evaluate $\mathrm{PB}$, a single-dose anticoagulant rodenticide bait was prepared with $0.25 \%$ experimental liquid brodifacoum (3-[3-(4'-Bromo[1-1'-biphenyl] -4-yl)-1,2,3,4tetrahydro-1-naphthalenyl]- 4-hydroxy-2H-1-benzo-pyran2-one) mixed with broken rice $(1: 49)$ to yield a $0.005 \%$ finished bait material. Six coconut husk bait holders with $50 \mathrm{~g}$ of treated bait were evenly spaced on the peripheral dikes of the 0.25-ha plot and checked weekly throughout the growing season. Fifty grams of bait were added to empty holders.

\subsection{Barrier methods}

LEB installation and operation procedures described by Ramos (1970) were followed. Chicken-wire fencing with $1.2-\mathrm{cm}$ mesh, $60-\mathrm{cm}$ tall, was nailed to $5 \times 5 \times 120-\mathrm{cm}$ wooden stakes at $1-\mathrm{m}$ intervals and placed about $0.5 \mathrm{~m}$ inside perimeter dikes (Fig. 1a). A 30 -cm wide galvanized iron sheet was nailed above the wire mesh fencing. Plastic insulators were fastened $45 \mathrm{~cm}$ above the ground to the wooden stakes for stretching two strands of 18-gauge galvanized iron wire. Electricity from a $12-\mathrm{V}$, heavy-duty car battery was passed through an inverter to generate up to $250 \mathrm{~V}$ alternating current from sunset to sunrise. Batteries were recharged daily. An electric bulb activated by disrupted current (usually from an electrocuted rodent or other small animal) alerted the IRRI crew.

NLEB installation and operation procedures followed the low cost, local material design of Reidinger et al. (1985). A $3-\mathrm{cm}$ mesh fish net, $50-\mathrm{cm}$ tall and supported at $1-\mathrm{m}$ intervals by $0.5 \times 3 \times 100-\mathrm{cm}$ bamboo stakes, was placed on dikes surrounding the plot (Fig. Ib). T-shaped wooden supports (insulators) were placed on the dike immediately outside the barriers at $1-\mathrm{m}$ intervals. Three strands of 18 -gauge, galvanized iron wire were stretched and placed in slits $(2.5 \mathrm{~cm}$ apart) made on the top portion of the wooden support. The inner (closest to barrier) and outer strands were 3 and $7 \mathrm{~cm}$ from the ground, respectively. Power was supplied $24 \mathrm{~h} /$ day from a 12-volt, heavy-duty car battery and passed through a Gallagher $^{\mathrm{R} 2}$ (Model E 12) high-powered battery fence energiser that released an intermittent pulse $\left(55\right.$ beats $\left.\min ^{-1}\right)$ of $1-5 \mathrm{kV}$. Batteries were recharged when power dropped below $8 \mathrm{~V}$.

One coconut husk bait holder with $50 \mathrm{~g}$ of $0.005 \%$ brodifacoum bait was maintained inside each of the four corners of each barrier to eliminate rodents that had entered the enclosed area prior to construction of an intact exclosure. When necessary, dikes were repaired and weeds under wires

\footnotetext{
${ }^{2}$ Reference to commercial products or entities does not imply endorsement by the authors or the U.S. Government.
} 


\section{A. LETHAL ELECTRIC BARRIER}

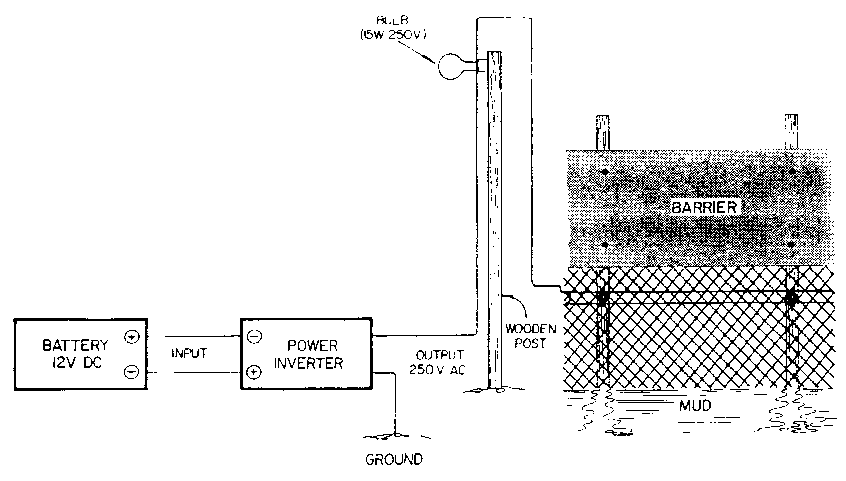

B. NONLETHAL ELECTRIC BARRIER

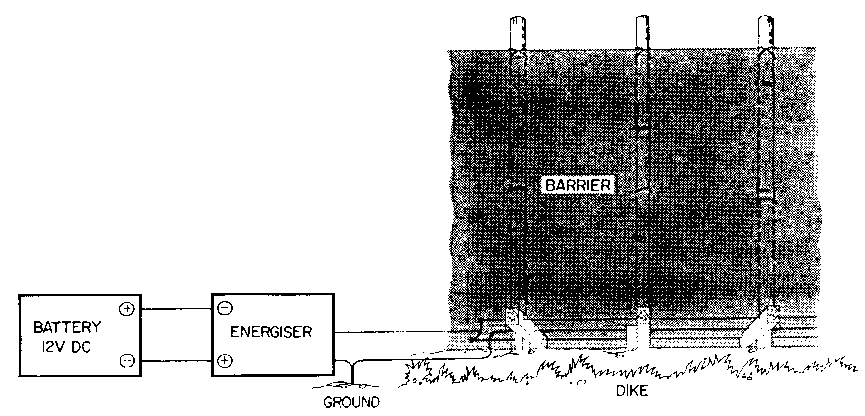

Fig. 1. Schematic diagram of the lethal (A) and nonlethal (B) electrificd barriers used in experimental rice fields of the International Rice Research Institute, Los Baños, Philippines.

were trimmed to prevent electrical grounding. All barriers were maintained from 4 WAT until harvest when they were removed.

\subsection{Evaluation of control measures}

Rodent damage and activity were measured in each plot at the tillering (3-4 WAT), flowering (8-9 WAT) and maturing (13-14 WAT) growth stages of rice. Damage was assessed using a cut-tiller index (Benigno, 1980). At each of the three growth stages, 200 rice hills per plot were randomly selected, and the number of rodent cut and uncut tillers was recorded. Damage was computed as a percent of examined tillers cut by rodents.

Rodent activity was measured using a tracking tile index modified by West et al. (1976). One-half of the upper side of white vinyl floor tiles $\left(15 \times 15 \mathrm{~cm}^{2}\right)$ were coated with a thin layer of printer's ink (Gestetner" mimeograph) mixed with a few drops of corn oil, if needed, to prevent drying. Ten inked tiles were evenly distributed $15-20 \mathrm{~m}$ apart in late afternoon along the inner side of the border dikes of the SB, PB, and NERC plots and along both the inside and outside fences of each LEB and NLEB plot. Tiles were examined the following morning and recorded as active if rodent footprints were present on the uninked portions. Cotton soaked in acctone was used to clean the uninked portion of the tiles. Inked tiles were set for 3 consecutive nights during each growth stage, and rodent activity was expressed as the percent of active tiles.

Statistical evaluations of the different rodent control techniques among three crop stages within two crop seasons were done with a split-plot design with two replications and an analysis based on percent of rodent activity and damage values transformed to the square $(x+0.5)$. Although reliable $F$-tests were obtained for crop stage and treatment $\times$ crop stage, the degrees of freedom for the error were insufficient for treatment alone.

\section{Results}

In maturing rice, mean damage in plots subjected to rodent control was three to four times greater during the wet season $(1.9-6.3 \%$ cut tillers) than during the dry season $(0.0-1.8 \%$ cut tillers) (Table 1). However, rodent damage as well as activity in NERC plots and rodent activity outside barricrs were generally higher in the dry season (Table 2). Mean tiller damage in all plots was highly correlated with mean rodent activity at the maturing $(r=0.93)$ but not at the flowering $(r=0.66)$ crop stage.

\subsection{Control methods}

Similar rodent damage and activity patterns occurred between the two baiting methods tested (Fig. 2). Baited plots 
Table 1

Mean (range) rice tiller damage $(\%)$ and rodent activity $(\%)$ near harvest $(n=2)$ in plots subjected to different rodent control methods in wet and dry seasons at the International Rice Research Institute. Los Baños. Philippines

\begin{tabular}{|c|c|c|c|c|}
\hline \multirow[b]{2}{*}{ Control method } & \multicolumn{2}{|l|}{ Wet season } & \multicolumn{2}{|l|}{ Dry season } \\
\hline & Tiller damage & Activity & Tiller damage & Activity \\
\hline Sustained baiting (SB) & $2.4(1.7-3.2)$ & $28.0(26.7-30.0)$ & $0.7(0.6-0.8)$ & $8.0(6.7-10.0)$ \\
\hline Pulsed baiting ( $\mathrm{PB}$ ) & $3.3(1.6-5.0)$ & $20.0(13.3-26.7)$ & $0.8(0.6-1.0)$ & $12.0(10.0-13.3)$ \\
\hline Nonlethal electrified barrier (NLEB) ${ }^{a}$ & $6.3(3.0-9.7)$ & $43.3(13.3-73.3)$ & $1.8(1.7-1.9)$ & $21.7(20.0-23.3)$ \\
\hline Lethal electrified barrier $(\mathrm{LEB})^{\mathrm{a}}$ & $1.9(0.4-3.3)$ & $3.3(0.0-6.7)$ & $0.0(0.0-0.0)$ & $0.0(0.0-0.0)$ \\
\hline No experimental rodent control (NERC) & $7.3(3.5-11.1)$ & $50.0(33.3-66.7)$ & $11.3(11.0-11.7)$ & $61.7(53.3-70.0)$ \\
\hline
\end{tabular}

Rodent activity measured inside the barrier.

Table 2

Mean rodent activity (\%) inside and outside lethal (LEB) and nonlethal (NLEB) electrified barriers at three growth stages of rice during wet and dry crop seasons at the International Rice Research Institute experimental fields in the Philippines

\begin{tabular}{|c|c|c|c|c|c|c|c|}
\hline \multirow[b]{3}{*}{ Treatment } & \multirow[t]{3}{*}{ Rice growth stage } & \multicolumn{4}{|c|}{ Mean rodent activity $(n=2)$} & & \\
\hline & & \multicolumn{2}{|c|}{ Wet season } & \multicolumn{2}{|c|}{ Dry season } & \multicolumn{2}{|c|}{ Mean $(n=4)$} \\
\hline & & Outside & Inside & Outside & Inside & Outside & Inside \\
\hline \multirow{3}{*}{$\begin{array}{l}\text { Lethal electrified } \\
\text { barrier (LEB) }\end{array}$} & Tillering & 1.7 & 6.7 & 15.0 & 15.0 & 8.4 & 10.9 \\
\hline & Flowering & 1.7 & 1.7 & 31.7 & 0.0 & 16.7 & 0.9 \\
\hline & Maturing & 31.7 & 3.3 & 41.7 & 0.0 & 3.7 & 1.7 \\
\hline \multirow{3}{*}{$\begin{array}{l}\text { Nonlethal electrified } \\
\text { barrier (NLEB) }\end{array}$} & Tillering & 8.3 & 1.7 & 13.3 & 11.7 & 10.8 & 6.7 \\
\hline & Flowering & 10.0 & 31.7 & 20.0 & 1.7 & 15.0 & 16.7 \\
\hline & Maturing & 36.7 & 43.3 & 25.0 & 21.7 & 30.9 & 32.5 \\
\hline \multirow{3}{*}{$\begin{array}{l}\text { No experimental } \\
\text { rodent control (NERC) }\end{array}$} & Tillering & & 1.7 & & 5.0 & & 3.4 \\
\hline & Flowering & & 50.0 & & 35.0 & & 42.5 \\
\hline & Maturing & & 50.0 & & 61.7 & & 55.8 \\
\hline
\end{tabular}

received 55-94\% less rodent damage compared with NERC plots. Very different rodent damage and activity patterns occurred between the two barrier methods tested. Only the LEB substantially reduced tiller damage and rodent activity through the maturing crop stage. While rodent activity inside LEB exclosures was lower than outside exclosures at the maturing growth stage, no such differences were found in NLEB plots (Table 2).

During the wet season, rodenticide bait consumption in SB and PB plots was low at the early tillering stage, peaked at the flowering stage, and declined to zero during the maturing stage (Fig. 3). In contrast, bait consumption during the dry season was greatest early in the tillering stage and declined gradually to zero after $10-11$ WAT.

\subsection{Cost-effectiveness}

Total estimated costs, including installation, operation, and maintenance requirements, varied from about $\$ 26 \mathrm{ha}^{-1}$ per crop season for SB to $\$ 1285 \mathrm{ha}^{-1}$ per crop season for the LEB (Table 3). Barrier methods required more numerous and expensive materials and the LEB, in particular, required intensive labour expenditures $\left(\$ 953.64 \mathrm{ha}^{-1}\right.$ per 80 -day crop protection period). Total estimated operational costs $\left(\$ 1018.67 \mathrm{ha}^{-1}\right.$ per 80 -day crop protection period) were about 40 times those of either baiting method. Total maintenance and installation costs for the NLEB and LEB were similar. The higher maintenance costs of the NLEB, largely due to dike repair (rodent burrows) and weed removal for preventing grounding of positive wires, were offset by decreased installation costs.

If effectiveness is defined as the percent of reduction in cut tillers compared to damage in plots with no experimental rodent control (NERC), a relative benefit : cost comparison between methods can be made. Ahmed et al. (1987) reported $\$ 370000$ worth of research data lost in one year at the IRRI farm due to rodent damage that occurred during the current study. Based on the assumptions that the $9.3 \%$ cut-tiller index from our "reference" plots in this study represents the damage level causing these monetary losses and that the reduced damage levels that we measured in this study reduce monetary losses proportionately, a benefit : cost ratio comparing the investment of each control method was derived (Table 4). Based on this estimation, baiting methods were much more cost-effective than barrier methods. The highest benefit: cost ratios were from SB $(47: 1)$ and PB (43: 1) plots, while the lowest were from $\operatorname{NLEB}(3: 1)$ and LEB (1:1) plots.

These benefit : cost ratios are based on 1980/81 prices for labour and materials; we believe it reasonable to assume that 

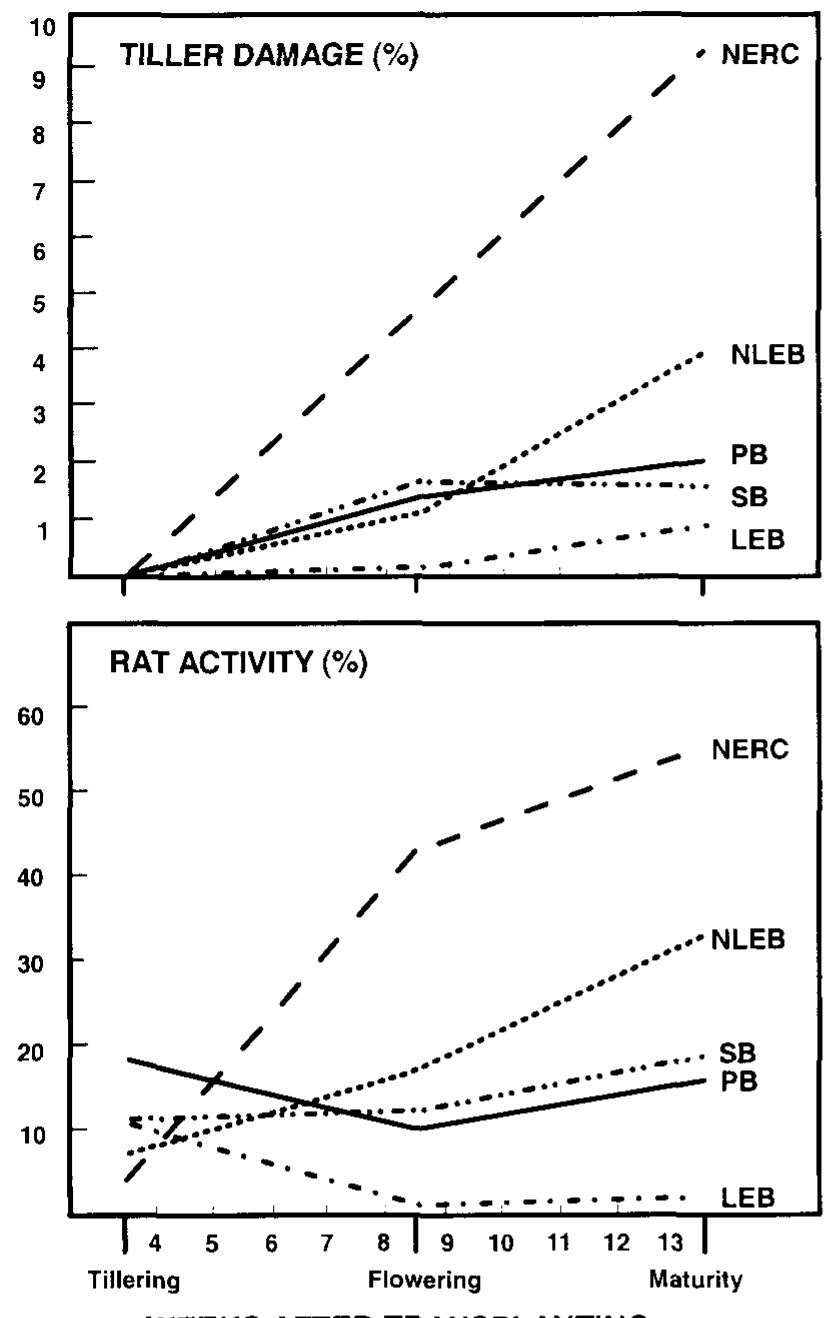

WEEKS AFTER TRANSPLANTING

Fig. 2. Mean rice tiller damage (\%) and rodent activity $(\%)$ at three crop stages in plots subjected to different rodent control methods during one wet and one dry crop season. SB-sustained baiting; PB pulsed baiting; NLEB - nonlethal electrified barrier; LEB-lethal clectrified barrier; and NERC no experimental rodent control.

these costs, as well as the costs of rice research have changed proportionally and that the ratios remain valid. Further work would be required to examine whether the application of newer rodent control technologies could achieve significant changes.

\section{Discussion}

Obvious seasonal differences in rodent activity and damage for all test plots were consistent with previously reported results from the IRRI farm (Uhler, 1967), cage tests (West et al., 1975b), and farmers' fields (Marges, 1972). Rodent populations are most likely to be lowest at the beginning of the wet season rice crop because of decreasing availability of food, shelter, and water after the previous dry season rice crop harvest. Reproduction normally increases during the

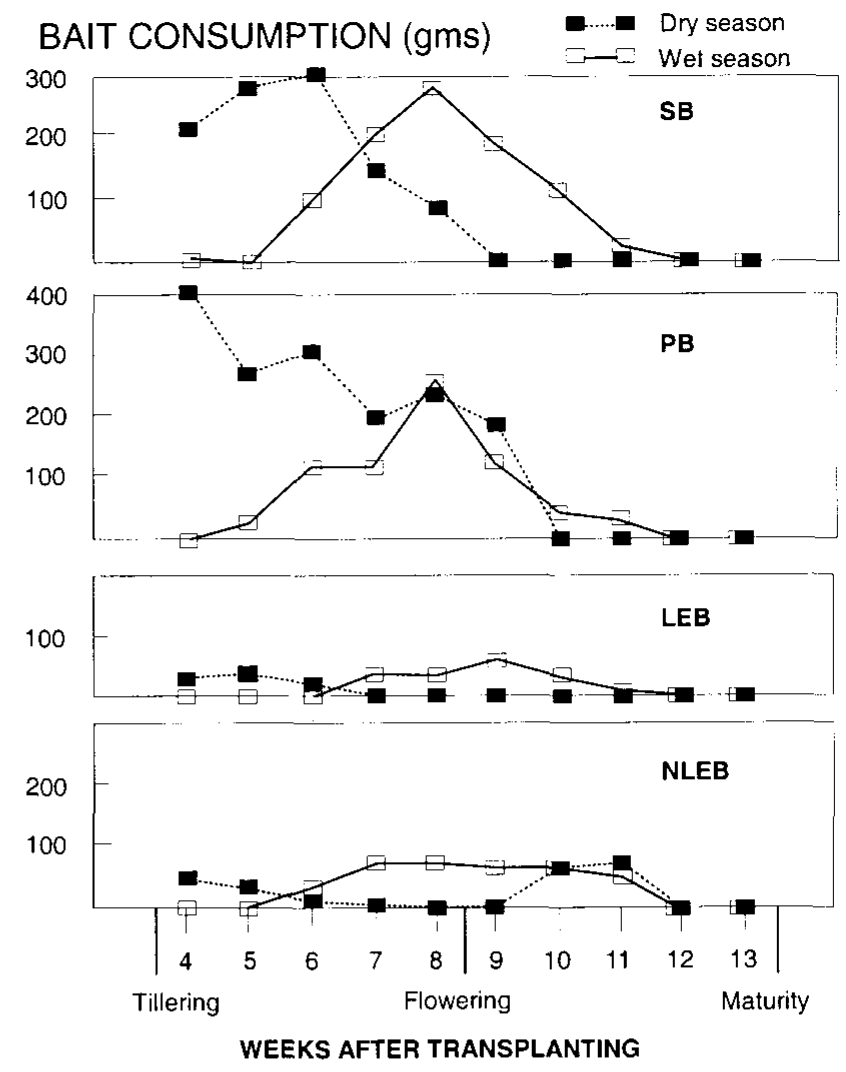

Fig. 3. Mean weekly bait consumption by rodents in 0.25 ha rice plots subjected to sustained baiting ( $\mathrm{SB}$ ), pulsed baiting ( $\mathrm{PB}$ ), nonlethal electrified barrier (NLEB), and lethal electrified barrier (LEB) during wet and dry crop seasons.

more favourable wet season and results in increased rodent numbers at the beginning of the dry season, which accounts for the higher bait consumption that occurred early in the dry season. Similarly, rodent activity, which reflects population density and movement, was much lower in the early wet season than in the early dry season. High rodent density and tiller damage in the unprotected NERC plots during the dry season were probably due to more rodents per unit of cultivated area, because there were fewer experimental plots on the IRRI farm at that time.

In most cases, high rodent activity resulted in correspondingly high rodent damage and bait consumption, while low rodent activity was associated with low rodent damage and bait consumption. This relationship confirmed the reliability of using tracking tiles for measuring rodent activity and using the results as an indicator of rodent abundance and subsequent crop damage. Tracking tiles were useful in many types of weather including all but the heaviest rainfall.

\subsection{Control methods}

Of the four rodent control methods, the LEB consistently resulted in lower rodent activity, bait consumption, and tiller damage, indicating that rodents had been excluded 
Tabie 3

Estimated costs per hectare (USS) of sustained baiting (SB), pulsed baiting (PB), lethal electrified barrier (LEB). and nonlethal electrified barrier (NLEB) used to reduce rodent damage during an 80-day rice crop protection period at the International Rice Research Institute experimental farm, Los Baños, Philippines. 1980-81

\begin{tabular}{|c|c|c|c|c|c|}
\hline \multirow[b]{2}{*}{ Item } & \multicolumn{4}{|c|}{ Estimated costs ${ }^{\mathrm{a}}$} & \multirow{2}{*}{$\begin{array}{l}\text { Life span } \\
\text { (yr) }\end{array}$} \\
\hline & $\overline{\mathrm{SB}}$ & $\overline{\mathrm{PB}}$ & LEB & NLEB & \\
\hline \multicolumn{6}{|l|}{ Installation requirements } \\
\hline Wooden post, $400 \mathrm{pc}$ & & & 26.49 & & 3 \\
\hline Chicken wire, $400 \mathrm{~m}$ & & & 36.69 & & 5 \\
\hline Galvanized iron sheet, $400 \mathrm{~m}$ & & & 23.31 & & 5 \\
\hline Plastic insulator, $400 \mathrm{pc}$ & & & 2.65 & & 5 \\
\hline Nails, No. $1-1 / 2$ & & & 0.66 & & 3 \\
\hline Bamboo stakes, $400 \mathrm{pc}$ & & & & 6.62 & 1 \\
\hline Fish net, $400 \mathrm{~m}$ & & & & 29.80 & 1 \\
\hline Wooden insulator, $400 \mathrm{pc}$ & & & & 13.25 & 2 \\
\hline Wire, 18 gauge, $800 \mathrm{~m}, 1200 \mathrm{~m}$ & & & 0.66 & 0.93 & 2 \\
\hline Labour- $-13,20$ man-days & & & 77.48 & 119.21 & - \\
\hline Battery, $12 \mathrm{~V}$, heavy-duty & & & 31.66 & 7.95 & 1,4 \\
\hline Power Model E-12 & & & & 19.87 & 10 \\
\hline Total Installation cost & & & 213.11 & 197.63 & \\
\hline \multicolumn{6}{|l|}{ Operational requirements } \\
\hline Flashlight and & & & 1.32 & & 5 \\
\hline batteries, $1.5 \mathrm{~V}, 18 \mathrm{pc}$ & & & 4.11 & & - \\
\hline Battery recharge, 75,4 times & & & 59.60 & 3.18 & - \\
\hline Labour, 160 man-nights & & & 953.64 & & $\ldots . .$. \\
\hline Total Operational cost & & & 1018.67 & 3.18 & \\
\hline \multicolumn{6}{|l|}{ Maintenance requirements } \\
\hline Coconut husk-11, 12,4,4 pc & 0.72 & 0.79 & 0.26 & 0.26 & 0.5 \\
\hline Coumachlor bait $-4 \mathrm{~kg}$ & 1.59 & - & - & - & - \\
\hline Brodifacoum bait- $5,1.8,2.7 \mathrm{~kg}$ & - & 13.91 & 5.03 & 7.55 & $-\ldots$. \\
\hline Labour- $-4,2,8,10$ man-days & 23.84 & 11.92 & 47.68 & 59.60 & - \\
\hline Total Maintenance cost & 26.15 & 26.62 & 52.97 & 67.41 & \\
\hline Total Cost/ha/80-day period & 26.15 & 26.62 & 1284.75 & 268.22 & \\
\hline
\end{tabular}

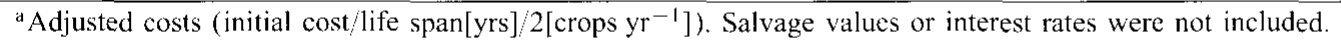

Table 4

Benefit : cost ratios of four control methods tested at the International Rice Research Institute, Los Baños, Philippines. Assumptions include $9.3 \%$ cut tillers (from this study) and $\$ 370000$ research data lost per year per 252 ha (from Ahmed et al., 1987)

\begin{tabular}{|c|c|c|c|c|c|c|}
\hline Control methods & $\begin{array}{l}\% \text { Cut } \\
\text { tillers } \\
A \\
\end{array}$ & $\begin{array}{l}\text { Damage } \\
\text { ratio } \\
B \\
\end{array}$ & $\begin{array}{l}\text { Losses } \\
(\$) \\
C\end{array}$ & $\begin{array}{l}\text { Benefits } \\
(\$) \\
D \\
\end{array}$ & $\begin{array}{l}\text { Costs } \\
(\$) \\
E \\
\end{array}$ & $\begin{array}{l}\text { Benefit: cost } \\
\text { ratio } \\
F\end{array}$ \\
\hline Sustained baiting (SB) & 1.6 & 0.172 & 63640 & 1216 & 26 & 47 \\
\hline Pulsed baiting (PB) & 2.0 & 0.215 & 79550 & 1153 & 27 & 43 \\
\hline \multicolumn{7}{|l|}{ Nonlethal electrified } \\
\hline barrier (NLEB) & 4.1 & 0.441 & 163170 & 821 & 268 & 3 \\
\hline \multicolumn{7}{|l|}{ Lethal electrified } \\
\hline barrier (LEB) & 0.9 & 0.097 & 35890 & 1326 & 1285 & 1 \\
\hline No experimental rodent control (NERC) & 9.3 & 1.0 & 370000 & 0 & $0^{*}$ & - \\
\hline
\end{tabular}

${ }^{*} B=A / 9.3$ or the ratio of $\%$ cut tillers with rodent control vs. $\%$ cut tillers without rodent control.

$C=B \times \$ 370000$ from Ahmed et al. (1987).

$D=(\$ 370000-C) / 252$ ha.

$E=$ cost per hectare per 80 -day period from Table 3 .

$F=D E$. 
from the protected rice crop. The NLEB provided good protection except in one of the four plots tested. Many rodent burrows suddenly appeared in the contiguous dike between this plot and an adjacent harvested rice field. Rodents burrowed under the NLEB and through the dike to enter the protected plot, which caused high levels of damage before the wet season harvest. The minimal baiting within this and other barrier plots was designed to (1) eliminate any rodents present prior to construction of the barrier, (2) monitor bait consumption as an indicator of rodent presence during the early crop growth stages, and (3) eliminate those few rodents that managed to enter the exclosure. This baiting was not designed to protect against a large influx of rodents late in the crop season-when mature rice plants are much more attractive to rodents than the bait material offered.

Burrowing under the LEB was limited by paddy water and lethal contact because the barrier was inside the paddyat least $15 \mathrm{~cm}$ deep and $50 \mathrm{~cm}$ from the dike. The NLEB method probably would have been more effective if a design allowing construction within the paddy had been used.

There was little difference in effectiveness between the two baiting methods tested. Both $\mathrm{SB}$ and $\mathrm{PB}$ reduced tiller damage in protected plots almost as well as the LEB.

\subsection{Cost-effectiveness}

Barrier costs per meter-particularly for the LEBare reduced if the size of the protected area is increased (Fig. 4). Installation and maintenance costs decreased with increased periphery, but the operational costs (the most expensive component of the LEB method) remained constant up to 6.25 ha (1000-m perimeter), thereby reducing the total estimated cost per unit length (or area enclosed). One person can maintain the LEB on a 6.25-ha plot during a 6-h work period. Beyond this size, operational costs per meter for the LEB increase substantially due to the additional labour required to patrol the fence. The extremely low operational costs of the NLEB, despite a $24-\mathrm{h} \mathrm{d}^{-1}$ operating capability, was advantagcous. Costs per hectare could be reduced even more for fenced areas over 20 ha (Shumake et al., 1979).

Baiting methods provided reasonable protection for the least cost. Installation and operation required inexpensive bait holders, rodenticide bait, and routine daytime labour. However, relying totally on baiting with no fences in areas larger than those tested in this study presents a potential risk of rodent damage to experimental rice.

\section{Recommendations}

Since we do not know the damage level tolerated within individual experimental fields, it is difficult to recommend a control method that would be acceptable to all researchers.

\section{COST/METER/SEASON (US \$)}
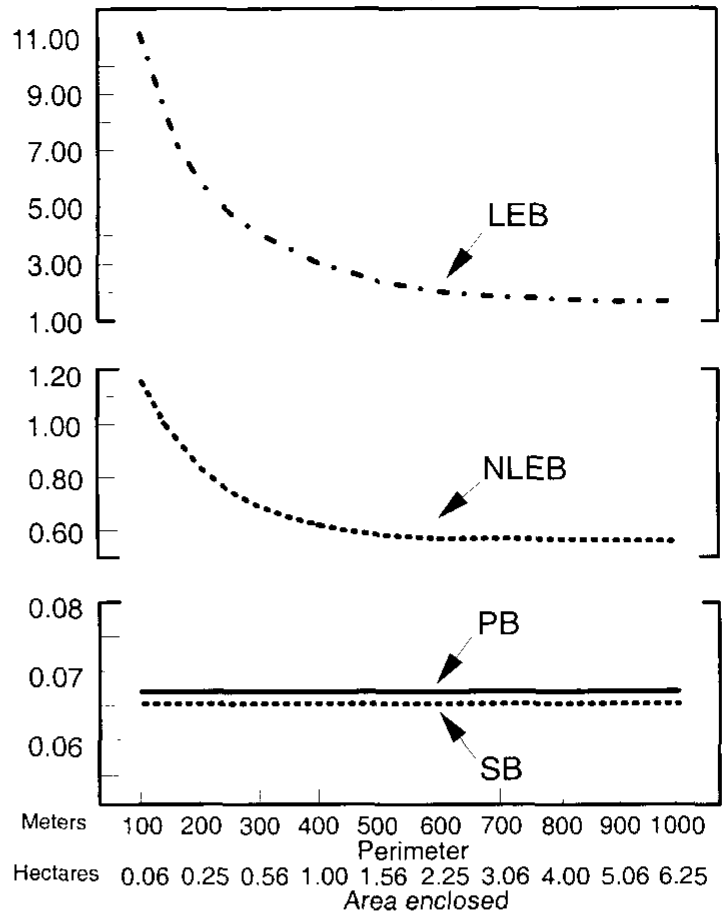

Fig. 4. Estimated cost of different rodent control methods in rice fields as a function of the perimeter or area to be controlled. SB-sustained baiting; PB-. pulsed baiting; NLEB-nonlethal electrified barrier; and LEB-lethal electrified barricr. Season is one 80-day crop protection period.

Some experimental plots can be subjected to much more rodent damage than others without the loss of any research results. Limiting rodent damage to $2 \%$ cut tillers or less is a reasonable objective in terms of both control cost and usable research data collected from the plots. All methods tested in this study, except the NLEB design, met that goal.

A barrier system combining the favourable components of the LEB and NLEB including an in-paddy placement of long-lasting materials with low maintenance and operational costs would be desirable. A chicken-wire fence placed in the paddy using a nonlethal electric pulse would contain these ideal components and significantly reduce the high operational costs of the LEB (see Shumake et al., 1979). A subsequent barrier/trap system developed and reported on some years later by Lam et al. (1990), and tested on the IRRI farm by Quick (1991), may offer another alternative to baiting in research plots requiring a high degree of protection from rodent damage.

Efficiency of both baiting methods used in this study could be increased by placement of bait holders within the paddy vs. on the dike. Unpublished data from the Philippines (M.W. Fall, personal communication) showed greater consumption of rice bait from containers placed within the paddy $1-2 \mathrm{~m}$ from the dike. 


\section{Acknowledgements}

Research was funded by the IRRI and the U.S. Fish and Wildlife Service, Denver Wildlife Research Center (now the USDA National Wildlife Research Center), through the U.S. Agency for International Development under PASA "Control of Vertebrate Pests" ID/TAB-473-1-67. We appreciate the support of the Philippine National Crop Protection Center, Los Baños, and comments provided by M.W. Fall, D.L. Nolte, and M.E. Tobin on previous drafts of this article.

\section{References}

Ahmed, M.S., Fiedler, L.A., Heinrichs, E.A., 1987. Economic losses by rats on experimental rice farms in the Philippines. Crop Protection 6. 271-276.

Benigno, E.A., 1980. Assessing crop damage caused by small mammals. In: Sanchez. F.F. (Ed.), Procecdings of the Symposium on Small Mammals: Problems and Control University of the Philippines at Los Baños, Laguna, Philippines, pp. 139148.

Dubock, A.C.. 1982. Pulsed baiting-A new technique for high potency. slow acting rodenticides. Vertebrate Pest Conference 10, 123-136.

Fall, M.W., 1982. Agricultural development and the ecology of rodent control. In: Alternative Strategies for Desert Development and Management, Proceedings of the UNITAR International Conference, Vol. 2, pp. 443-451, Sacramento, CA, 1977. Pergamon Press. New York.

Lam. Y.M., Supaad, M.A., Chang, P.M., Mohamed, M.S., Goh, C.S., Radzi, H., 1990. An innovative approach for protecting rice against severe rat depredation. In: Proceedings of the 3 rd International
Conference on Plant Protection in the Tropics (Ed. by Malaysian Plant Protection Society) Vol. 2. pp. 41-49, Genting Highlands. Malaysia, 1990.

Marges, B.E., 1972. Reproduction and seasonal abundance of the rice field rat (Raths rattus minklanensis Mearns) at Siniloan. Laguna. M.S. Thesis, University of the Philippines at Los Baños. Laguna, Philippines, 43pp.

Quick. G.R., 1991. Unpublished Report, The IRRI active barrier system (ABS) for rodent control, Agricultural Engineering Division, The International Rice Research Institute, Los Baños. Laguna, Philippines, 6pp.

Ramos, F.V., 1970. The electric rat fence. In: Rice Production Manual, International Rice Research Institute, Los Baños, Laguna. Philippines, pp. $212 \cdot 216$.

Reidinger Jr., R.F., Libay, J.L., Kolz, A.L., 1985. Field trial of an electrical barricr for protecting rice fields from rat damage. Philippine Agriculturist 68, 169-179.

Shumake, S.A., Kolz, A.L., Reidinger, R.F., Fall, M.W.. 1979. Evaluation of nonlethal electric barriers for crop protection against rodent damage. In: Beck, J.R. (Ed.). Proceedings of the 2nd Symposium on Test Methods for Vertebrate Pest Control and Management Materials, Sacramento, CA, pp. 29-38.

Uhler, L.D., 1967. The reproduction of Rathis rattus mindanensis at the International Rice Research Institute, College, Laguna, Philippines. Philippine Agriculturist 51, 576-580.

West, R.R., Fall, M.W., Libay, J.L., 1975a. Reducing interactions among rats to improve bait acceptance. Philippine Agriculturist 59, 31-36.

West. R.R., Fall, M.W.. Libay, J.L., 1975b. Tiller cutting behavior of rats in growing rice. Philippine Agriculturist 59, 27-30.

West. R.R., Fall, M.W., Benigno, E.A.. 1976. Comparison of tracking tiles and snap traps for obtaining population indices of Rutus rattus mindanensis in the Philippines. Philippine Agriculturist 59. $379-386$. 